\title{
Attitudes and Perceptions Towards Nursing Profession Among Nursing Students at Hue University of Medicine and Pharmacy
}

\author{
Ba Hai Mai ${ }^{1}$. Thi My Yen $\mathrm{Ho}^{2}$. Thi Thu Thao Nguyen ${ }^{2}$ \\ Le Thi Thanh Phan ${ }^{2} \cdot$ Thi Huong Hoang ${ }^{2}$. Nguyen Thi Anh Phuong ${ }^{3}$ \\ ${ }^{1-3}$ Hue University of Medicine and Pharmacy, Vietnam
}

\section{ABSTRACT}

Objectives: To describe the attitudes and perceptions toward nursing profession among nursing students at Hue University of Medicine and Pharmacy (Hue UMP).

Method: The mixed method study involved 319 nursing students from first to fourth-year. Quantitative data was collected by using the Attitudinal Scale for Nursing Profession, and participants' subjective perception of nursing profession was collected by asking participants questions such as: "How do you feel about nursing and nursing profession?"

Results: The quantitative results showed that the mean score of nursing students' attitudes toward nursing profession was $148.76(S D=+37.29)$. The average score on satisfaction for nursing profession varies from 40 to 200. The qualitative findings show perceptions classified under 2 emergent themes: 1) A career that requires passion and professionalism 2) High-pressure and a boring career.

Conclusion: These findings provide a preliminary understanding of nursing students' attitudes and perceptions toward the nursing profession. The study has implications for both the nursing professors and university: Curricula have to emphasize ways of enhancing student's positive awareness of the contemporary roles and values of the profession to students. Collaborative studies with other Universities and Colleges will assist in developing stimulus material and learning strategies that will enhance the value of the role of nurses in contemporary Vietnamese health care. 


\section{INTRODUCTION}

Nurses constitute the backbone of the healthcare system in all countries. Nursing is a critical factor in determining the quality of care in hospitals and the nature of patient outcomes (Wunderlich, Sloan, \& Davis, 1996). In Vietnam, the total number of nurses is about 141,494 working in all 1,304 medical settings, medical institutes and Universities (Ministry of Health, 2015). They encompass the largest group of healthcare personnel employed in the health sector (Ministry of Health, 2015). Unfortunately, a large number (about 70\%) of Vietnamese nurses possess only a secondary level nursing education so they work in hospitals and clinical settings and focus on providing medical assistance (Jones, O'Toole, Hoa, Chau, \& Muc, 2000; Ministry of Health, 2015). In reality a nursing career is very demanding, with nurses suffering from a lot of pressure in their working environment, dealing with symptoms related to patients' illnesses and conditions; they experience low job satisfaction. Although nursing plays an important role in maintaining people's health, nursing staff are not well recognized by society to the extent that they deserve. Therefore, this has a certain impact on the value of the nursing profession, the extent of love felt for the profession, and passion for study among nursing students.

A literature review shows previous studies that have identified nursing students' attitudes and levels of dissatisfaction with the profession; the majority are not interested in studying nursing (Kathreena, et.al, 2015; Wajed, \& Erik, 2017). Although a number of studies on students' perceptions of nursing and factors influencing it were reported in other countries, this is not so in Vietnam. Recent studies of nursing students' perceptions of nursing profession were also limited. According to a study from 2005-2007 on the attitudes of nursing students towards the nursing profession at Hanoi Medical University (HMU), Hue University of Medicine and Pharmacy (Hue UMP), Ho Chi Minh City University of Medicine and Pharmacy (HCM UMP), the result showed that the satisfaction levels within nursing was 50.7\%; satisfaction with a nursing career was declining over years of study, $61 \%$ in the first year, $62 \%$ in the second, $49 \%$ in the third and $32 \%$ in the fourth year (Phi, 2011). Moreover, there are many students who select to study nursing because of influence from family, friends and teachers. They do not aspire to engage in the learning process and have no interest in practice in the hospital. Therefore, it is necessary to conduct this study in Vietnam at this time, especially at Hue UMP. It is expected that the results of this study will provide not only information for nursing educators in order to raise the awareness of the value of the nursing profession but also create a more interesting and motivating learning process. Managers of the university need to investigate ways to improve students' satisfaction and encourage them to enter the nursing workforce after graduation.

\section{METHOD}

Three-hundred-and-nineteen nursing students from four nursing classes consented and voluntarily participated in the study: 77 from Year 1; 132 from Year 2; 77 from Year 3; 33 from Year 4. They were informed about the aims, benefits of the study as well as the data collection procedure.

\section{Research Design}

The mixed method study descriptive study was conducted to ascertain students' attitudes and perceptions toward the nursing profession. Research material: The questionnaire Attitudinal Scale for Nursing Profession 
(ASNP) with $\mathrm{n}=40$ items, developed by Ipek Coban and Kasikci in 2011was the standardized tool used. The translation and back-translation technique was used to convert the English version to Vietnamese (Burns \& Grove, 2009). There are three sub-sets of questions within the ASNP: "Properties of nursing profession" ( $\mathrm{n}=18$ items); "Preference for nursing profession" ( $n=13$ items); and "General position of nursing profession" ( $n=9$ items). Students responded to a Likert scale from 1 Strongly disagree, 2 Disagree, 3 Neutral, 4 Agree, 5 Strongly agree. The average score on satisfaction for nursing profession varies from 40 to 200. The Cronbach coefficient value of the instrument was .76, which was acceptable for this study.

To better understand nursing students' perceptions towards the nursing profession a qualitative descriptive approach was also used by interviewing to 16 nursing students who were randomly recruited: 4 students from each class. Each student consented and volunteered to participate after being informed about the aims and the the interview procedures. Each interview was audiotaped and lasted from 20 to 30 minutes, focusing on the question "How do you feel about nursing and Nursing profession?".

\section{Data Analysis}

The descriptive statistics analysis included the characteristics of the participants and their attitudes towards nursing profession. Qualitative content analysis began with interview files transcribed from recordings to text to explore significant statements consistent with the study aim. Emergent themes were organized as clusters of statements with similar meaning.

\section{Ethical Considerations}

The study was approved by the Hue University of Medicine and Pharmacy Committee on Ethics and Research.

\section{RESULTS}

\section{Attitudes Towards Nursing Profession Among Nursing Students}

The results from Table 1 show that most students have a favorable attitude towards the nursing profession (mean score $148.76(\mathrm{SD}= \pm 37.29)$. Responses indicating a favorable attitude accounted for $62.07 \%$ of students; Moderately favorable attitudes accounted for $36.36 \%$ of students. Responses within questionnaire sub-categories in Table 2 showed that students' responses to items on the "Properties of nursing profession" attracted the highest with mean score $=4.17(\mathrm{SD}= \pm 0.56)$, and items on "Preference to nursing profession" the lowest with mean score $=3.02(\mathrm{SD}= \pm 0.33)$.

Table 1. Attitudes towards Nursing profession

\begin{tabular}{|c|c|c|c|c|c|}
\hline Categories & Range score & $\begin{array}{l}\text { Total } \\
\text { score }\end{array}$ & SD & $\mathrm{n}$ & $\%$ \\
\hline Unfavorable & $40.00-93.33$ & 148.76 & 37.29 & 5 & $1.57 \%$ \\
\hline $\begin{array}{l}\text { Moderately } \\
\text { favorable }\end{array}$ & $93.34-146.67$ & & & 116 & $36.36 \%$ \\
\hline Favorable & $146.68-200.00$ & & & 198 & $62.07 \%$ \\
\hline
\end{tabular}


Table 2. Results of Attitudinal Scale for Nursing profession

\begin{tabular}{|c|c|c|c|c|c|c|}
\hline \multirow{3}{*}{ Grade } & \multirow{2}{*}{\multicolumn{2}{|c|}{$\begin{array}{c}\text { Attitude on } \\
\text { "Properties of nursing profession" }\end{array}$}} & \multirow{2}{*}{\multicolumn{2}{|c|}{$\begin{array}{c}\text { Attitude on } \\
\text { "Preference to nursing profession" }\end{array}$}} & \multirow{2}{*}{\multicolumn{2}{|c|}{$\begin{array}{c}\text { Attitude on } \\
\text { "General position of nursing profession" }\end{array}$}} \\
\hline & & & & & & \\
\hline & Mean + SD & Mean\% & Mean + SD & Mean\% & Mean + SD & Mean\% \\
\hline The first year & $4.08 \pm .64$ & 81.6 & $2.99 \pm .34$ & 59.8 & $3.73 \pm .61$ & 74.6 \\
\hline The second year & $4.26 \pm .65$ & 85.2 & $3.05 \pm .34$ & 61.0 & $3.81 \pm .48$ & 76.2 \\
\hline The third year & $4.11 \pm .37$ & 82.2 & $3.03 \pm .33$ & 60.6 & $3.84 \pm .41$ & 76.8 \\
\hline The fourth year & $4.21 \pm .29$ & 84.2 & $2.93 \pm .23$ & 58.6 & $4.06 \pm .32$ & 81.2 \\
\hline Total score & $4.17 \pm .56$ & 83.4 & $3.02 \pm .33$ & 60.4 & $3.82 \pm .49$ & 76.4 \\
\hline
\end{tabular}

Maximum mean score $=5$, Minimum mean score $=1$

\section{Nursing students' perceptions towards nursing profession}

The two emergent superordinate themes from the qualitative findings of this study were labelled: 1) A career requires passion and professional work, and 2) A highpressure and boring career.

Nursing is a career that requires passion and professional work

The findings from Figure 1 showed sub-themes within this superordinate theme included: An interesting Profession; professional values; and a need to work professionally and proactively. In addition, students said that nursing was a promising career, adding that "It will probably be more respected" and that there were "more job opportunities, more respected people".

\section{Nursing is a high-pressure and boring career}

The findings from Figure 2 also showed that while there were many students who were positive about nursing, there were also those who thought that nursing was "a stressful and boring profession". It was suggested that nursing was always dependent on the doctor; not independence; the job is not respected, and the pressure from work those affect students' learning processes.

\section{DISCUSSION}

\section{Attitudes towards Nursing profession among Nursing students}

The quantitative results of this study reveal a favorable attitude towards nursing profession among nursing students. This was consistent with recent research which found that $65.4 \%$ of nursing students had a positive attitude and $34.6 \%$ a neutral attitude about nursing (Ali, Zahra, \& Abbas, 2012). This result is consistent with study by Lakhveer Kaur, Kanika and Ajesh Kumar's (2016) in which most students reported favorable attitudes to the nursing profession. However, this study finding was little higher than that reported by Phi (2011), in which $50.7 \%$ of nursing students were satisfied with the nursing profession. Zhang and Petrini (2008) found that 53.3\% of nursing students had a positive attitude towards their careers.

\section{Nursing Students' Perceptions towards Nursing Profession}

The Hue UMP results showed that their students have formed perceptions of the nursing profession like findings from other similar studies (Nguyen et al., 2016; McMillan, Park, Yoon, 2018). In terms of positive thinking, students perceived that nursing is a career that requires passion and professional approaches to work. The results of the 
study showed that many students were interested in the nursing profession, which is consistent with research by Ali Noruzi Koushali, et al., (2012) suggesting "Nursing tasks are enjoyable". With respect to perceptions of the value of the career's, many students said that "nursing is extremely important in the health care system". This result was consistent with the report by Banaderakhshan, Azizi, Mehrabi, and Mortazvi in 2005 which suggested that "Nursing is a profession needed in the society". Commenting on another aspect of the questionnaire "nursing needs to work professionally and proactively a respondent noted: "Nursing care is not only (about) physical care, but it is also mental (about) care and being patient advocates". This view was consistent with that from a study by Alexandros Petrou et al. (2017) in which nursing care was described as offering psychological and emotional support, “.... when you care about the other person and you take care of him/her with sensibility", and "...to love and to care for...the protection and the respect.... Similarly, Taiwanese nurses' perceptions of caring include inspiring hope in patients, having patience and respecting patients' culture (Tsai, Wang \& Chou, 2015).

In term of negative thinking, respondents perceived that the nursing profession is a high pressured and boring career. This finding is in accord with study findings by Nasrin, Soroor and Soodabeh (2012) in which students who were not interested in the nursing profession thought that "nursing care is boring". In addition, students perceived that “...the nursing function of co-operation between doctor and nurse has not been maximized, (it) mainly works when they follow the doctor's orders". This is consistent with a recent study the finding showed that nurses follow the physicians' orders without question (Achilles, 2009). Moreover, in this current study, the majority of the students perceived that providing nursing care was a job that was not respected by society; this is similar to findings from the study by Parandeh and Khaghanizade (2016). In addition, the views that nursing was a risky or difficult and stressful job is consistent with the findings of Nasrin, et al. (2012); and Nebhinani, Nebhinani, Tamphasana, and Gaikwad (2013). These study findings may provide suggestions for nurse educators to rethink and develop stimulus material within nursing curricula that focusses on enhancing student's positive attitudes and awareness and thus provide preliminary understandings to nursing students about the values of nursing profession.

\section{CONCLUSION}

The results of this study showed a range of attitudes and perceptions towards nursing profession among nursing students. The extent to which these views existed because the respondents did not have a fully formed appreciation of nature and scope of the nursing profession has not been fully explored. While these views are not unreasonable as the students in the 'process of becoming a nurse', it is also not unreasonable for students to express a range of views. Expression of professional values and attitudes may greatly impact the extent of the full suite of abilities that need to expressed within students' academic learning outcomes; these outcomes need to reflect international profiles of contemporary professional nursing practice. Educators can use the feedback about attitudes and perceptions provided by the participants in the current study and find exemplars as stimulus material for nursing roles, functions and interventions that challenge the cultural stereotypes of the profession. Nurses can lead their profession in enhancing positive attitude towards their profession by using nursing role models that are seen as 'enquiring collaborators' with their medical and 
allied health peers. Finally, further research is needed on the articulation of learning outcomes consistent with the full suite of abilities that are central to quality nursing practice.

\section{ACKNOWLEDGMENTS}

The authors express thanks to Professor Margaret McMillan, the University of Newcastle, Australia, for support in developing this article.

\section{REFERENCES}

Achilles, K. (2010). Image of nursing profession as viewed by secondary school students in Ilala district, Dar-es-Salaam. The Dar-es-salaam Medical Students' Journal, 17(1), 12-18.

Ali, N. K., Zahra, H., \& Abbas, E. (2012). Comparison of nursing students' and clinical nurses' attitude toward the nursing profession. Iran Journal Nursing Midwifery Research, 17, 375-380.

Banaderakhshan, H., Azizi, F., Mehrabi, Y., \& Mortazvi, F. (2005). Comparison of awareness, attitude, and professional function of graduates and senior nursing students. Journal of Medical Education Winter, 6(2), 141-147.

Burn, N., \& Grove, S. K. (2009). The practice of nursing research: Appraisal, synthesis, and generation of evidence (6th ed). St. Louis, MO: Saunders Elsevier.

Coban, I. G., \& Kasikci, M. (2011). Development of the attitude scale for nursing profession. International Journal of Nursing Practice, 17, 518-524.

Jones, P. S., O’Toole, M. T., Hoa, N., Chau, T. T., \& Muc, P. D. (2000). Empowerment of nursing as a socially significant profession in Vietnam. Journal of Nursing Scholarship. 32, 317-321.

Kathreena, M. U., Jaslyn, J. D., Jasmine, M. L., \& Sonia, K. S. L. (2015). A study to assess the attitude towards nursing profession among the nursing students in the selected college at mangalore. ScopeMed. 5(10), 217-220.
Kaur, L., Kanika, \& Kumar, A. (2016). Assess the attitude of nursing students towards nursing profession. International Journal of Applied Research, 2(6), 738-741.

McMillan, M., Park, M. Y., \& Yoon, S. (2018). Constructing Curricula: Rational choices around the use of simulations for optimal outcomes for students. Journal of Problem-Based Learning; 5(1), 37-44.

Ministry of Health [MOH]. (2015). Planning for development human resource in health care system in 2015 - 2020. Retrieved from http://kcb.vn/vanban/quyet-dinh-so2992qd-byt-ngay-17072015-cua-bo-y-te-ve-phe-duyet-kehoach-phat-trien-nhan-luc-trong-he-thong-kham-benhchua-benh-giai-doan-2015-2020

Nasrin, H., Soroor, P., \& Soodabeh, J. (2012). Nursing challenges in motivating nursing students through clinical education: A grounded theory study. Nursing Research and Practice, 2012. doi.org/10.1155/2012/161359

Nebhinani, M., Nebhinani, N., Tamphasana, L., \& Gaikwad, A. D. (2013). Nursing students' attitude towards suicide attempters: A study from rural part of northern India. Journal of Neurosciences in Rural Practice, 4(4), 400-407.

Nguyen, T.A.P., Kang, S., Ho, T.T.T., Mai, B.H.,, Vo, T.D.B., \& Nguyen, V.Q.H. (2016). Problem-based learning in nursing education at Hue university of medicine and pharmacy, Vietnam: Perspective and needs assessment. Journal of Problem-Based Learning. 3(1), 9-14.

Parandeh, A., \& Khaghanizade, M. (2016). Nurses' human dignity in education and practice: An integrated literature review. Iran Journal Nursing Midwifery Research, 21, 1-8.

Petrou, A., Sakellari, E., Psychogiou, M., Karassavidis, S., Imbrahimet, S., Savvidis, G., \& Sapountzi-Krepia, D. (2017). Nursing students' perceptions of caring: A qualitative approach. International Journal of Caring Sciences, 10(3), 1148-57.

Phi, T. N. T. (2011). A study of nursing student about attitudes toward to nursing profession and develop intervention strategies. National Library of Vietnam. Retrieve from http:// luanan.nlv.gov.vn/luanan?a=dઐd=TTcFfqyxKEUu2011

Tsai, Y.C., Wang, Y.H., \& Chou, LN. (2015). Caring behaviors exhibited by Taiwanese nurses. International Journal of Caring Sciences, 8, 317- 324. 
Tuan, M. (2016). The health sector moves forward to improve the quality of nursing education in health facilities. Retrive from http://t5g.org.vn/nganh-y-te-tien-toi-nang-cao-chat-luongdao-tao-dieu-duong-trong-cac-co-so-y-te

Zhang, M. F., \& Petrini, M. A. (2008). Factors influencing chinese undergraduate nursing students' perceptions of the nursing profession. International Nursing Review, 55, 274-280.

Wajed, A.H., \& Erik, H. L. S. (2017). Knowledge, attitude and intention towards nursing profession among pre-clinical students. Journal of Health Specialties. 5(3), 135-141

Wunderlich, G.S., Sloan, F., \& Davis, C.K (1996). Nursing staff in hospitals and nursing homes: is it adequate. Washington, DC: National Academy Press. 
